\title{
A case of sarcoidosis associated with chronic eosinophilic pneumonia
}

\author{
Halil Yanardag ${ }^{1}$, Cuneyt Tetikkurt $^{2 *}$, Aslı Sezgin $^{1}$, Ertuğrul Oruc $^{3}$, Muammer Bilir $^{1}$ \\ ${ }^{1}$ Department of Internal Medicine, Cerrahpasa Medical Faculty, Istanbul University, Istanbul, Turkey \\ ${ }^{2}$ Department of Pulmonary Diseases, Cerrahpasa Medical Faculty, Istanbul University, Istanbul, Turkey; \\ *Corresponding Author: tetikkurt@gmail.com, tetikkurt@superonline.com \\ ${ }^{3}$ Department of Pathology, Cerrahpasa Medical Faculty, Istanbul University, Istanbul, Turkey
}

Received 2 December 2013; revised 1 January 2014; accepted 25 January 2014

Copyright (C) 2014 Halil Yanardag et al. This is an open access article distributed under the Creative Commons Attribution License, which permits unrestricted use, distribution, and reproduction in any medium, provided the original work is properly cited. In accordance of the Creative Commons Attribution License all Copyrights (C) 2014 are reserved for SCIRP and the owner of the intellectual property Halil Yanardag et al. All Copyright (C) 2014 are guarded by law and by SCIRP as a guardian.

\section{ABSTRACT}

A 78-year-old woman was referred to our university hospital due to dry cough, fever, and weight loss. Laboratory revealed blood eosinophilia, high ESR, CRP and LDH. Rheumatologic markers were negative. Chest $X$-ray showed ground glass opacities in upper lobes. Uveitis developed in the left eye 1 week after admission. Thorax CT revealed ground glass opacities, reticular appearence in the upper lobes, enlarged axillary and mediastinal lymph nodes. Bronchoalveolar lavage $C_{4} / C_{8}$ was 2.1 and had $48 \%$ eosinophils. Histopathologic examination revealed eosinophilic infiltration and non-caseating epitheloid granulomas in the lung and mediastinal lymph nodes without vasculitis. Symptoms, blood eosinophilia and initial thorax CT findings improved after two months of methylprednisolone treatment. Chronic eosinophilic pneumonia is a rare disease characterized by systemic and pulmonary manifestations. It may be associated with other diseases.

\section{KEYWORDS}

\section{Sarcoidosis; Chronic Eosinophilic Pneumonia; Pulmonary Eosinophilia}

\section{INTRODUCTION}

Idiopathic chronic eosinophilic pneumonia (CEP) is a rare disease characterized by pulmonary manifestations, eosinophilia, peripheral opacities on chest X-ray with a prompt response to steroid treatment [1-6]. CEP may be associated with other diseases [7,8]. Association of CEP with sarcoidosis is very unusual $[9,10]$.

We report the case of a patient with coexisting sarcoidoisis and chronic eosinophilic pneumonia along with review of the literature.

\section{CASE REPORT}

A 78-year-old woman was hospitalized in September 2013 for dry cough, fever, and, weight loss of $6 \mathrm{~kg}$ over the last 4 months. Personal history included hypertension of 15 years. She was a nonsmoker. The patient was cachectic with loss of skin turgor. Blood pressure was 180/100 mm Hg. Respiratory rate was 18/minute. Physical examination revealed fine crackles over the left bazal zone, enlarged cervical, axillary and inguinal lymph nodes. Oxygen saturation was $94 \%$ on room air.

Laboratory data on admission included eosinophilia $\left(2760 / \mathrm{mm}^{3}, 25.3 \%\right.$, WBC: $\left.10.870 / \mathrm{mm}^{3}\right)$, mild normocytic anemia, a high ESR $(117 \mathrm{~mm} / \mathrm{h})$, a high CRP (62 $\mathrm{mg} / \mathrm{L}$ ) and a high LDH (670 IU/L) level. Chest X-ray revealed bilateral upper lobe ground glass opacities. Blood smear showed increased number of eosinophils (Figure 1). Rheumatologic markers and precipitating IgG antibodies were negative. Serum ACE was $67.7 \mathrm{U} / \mathrm{L}$ (normal: 8 - $52 \mathrm{U} / \mathrm{L}$ ). Pulmonary function tests and DLCO were within normal limits. IgE was $200 \mathrm{IU} / \mathrm{L}$.

In the first week of her admission redness and pain developed in the left eye. Opthalmologic consultation revealed anterior uveitis. Thorax CT disclosed ground glass opacities, reticular appearence with intertistial thickening in both upper lobes, axillary and mediastinal enlarged lymph nodes (Figure 2). PET/CT revealed increased FDG uptake in the mediastinal lymph nodes and bone marrow. Aspiration biopsy showed normocellular bone marrow. Right axillary lymph node biopsy demonstrated non-caseiting granulomas, Langerhans giant 


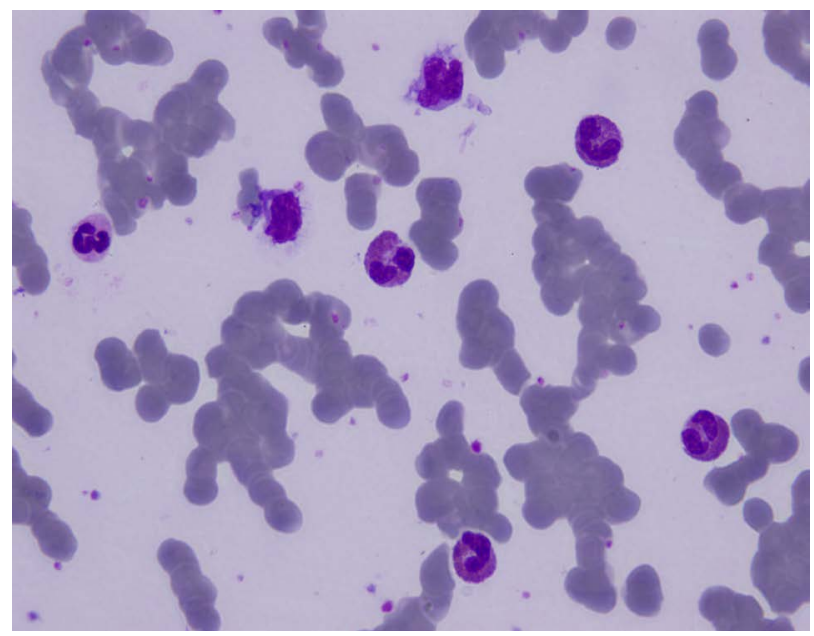

Figure 1. Blood smear showing increased number of eosinophils.

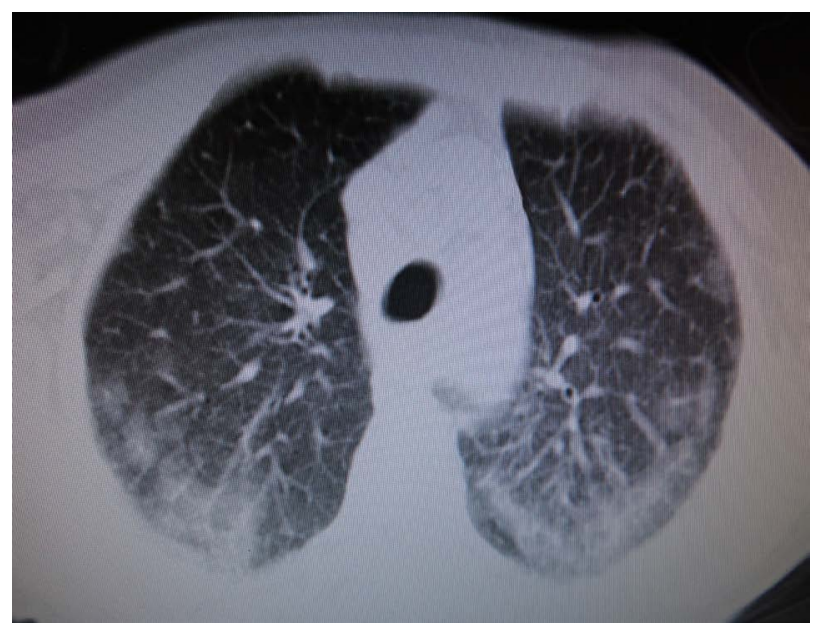

Figure 2. CT revealing ground glass opacities in the upper lobes.

cells, asteroid and Schaumann bodies compatible with sarcoidosis (Figure 3). Bronchoalveolar lavage had increased number of eosinophils (48\%) and $\mathrm{CD}_{4} / \mathrm{CD}_{8}$ ratio was 2.1. Culture and smear of BAL were negative for bacteria, acid-fast bacilli or fungi. Stool examination for parasites was negative. Pathology of the transbronchial lung biopsy specimen revealed non-caseating epitheloid granulomas and eosinophilic infiltration.

Based on these findins, a diagnosis of sarcoidosis with coexisting chronic eosinophilic pneumonia was made. The patient was commenced on $36 \mathrm{mg}$ methylprednisolone daily. Patient symptoms, hematological findings (eosinophil count decreased to $310 / \mathrm{mm}^{3}, 3 \%$ ), BAL eosinophilia (eosinophil ratio decreased to 8\%) and CT findings promptly improved after two months of treatment (Figure 4). The steroid dose was gradually decreased over the following 12 months with no evidence of recurrence.

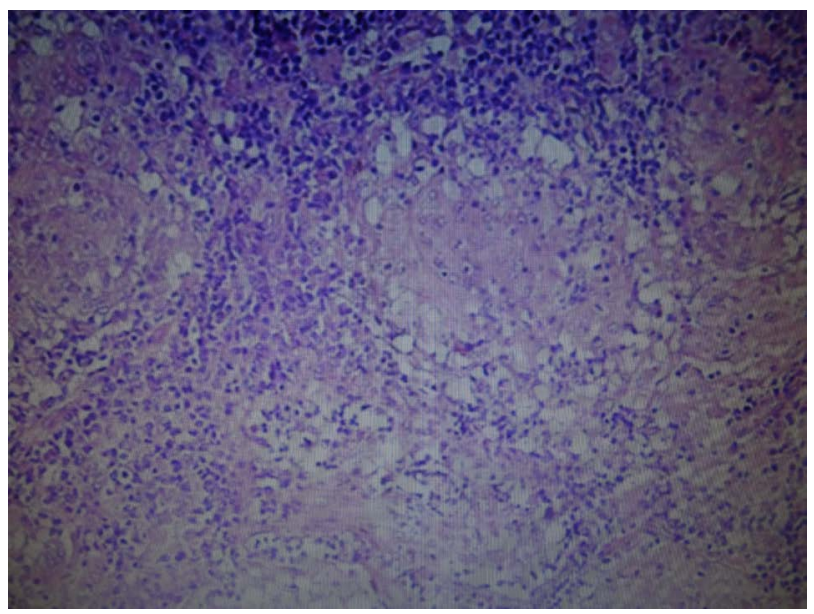

Figure 3. Axillary lymph node biopsy revealing non-caseiting granulomas with epitheloid histiocytes in the central areas (H.E, $\times 20$ ).

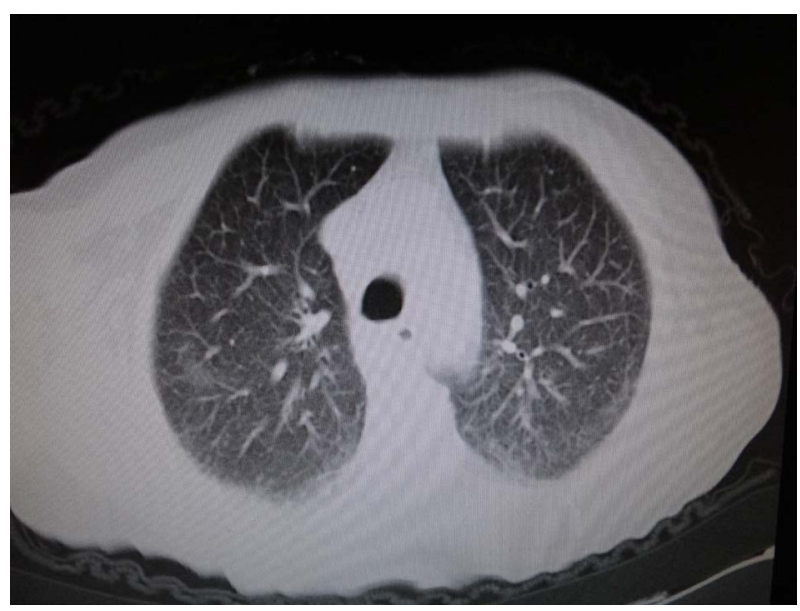

Figure 4. Resolution of CT findings after treatment.

\section{Discussion}

Our patient had clinical, radiological and pathological features of sarcoidosis associated with chronic eosinophilic pneumonia. Causes for eosinophilia such as drugs and infections were ruled out in this case. There was no evidence of vasculitis in the biopsy specimes. Consequently, idiopathic chronic eosinophilic pneumonia in regard to symptoms (weight loss, fever), pulmonary manifestations, blood eosinophilia, radiologic findings, exclusion of other etiologies with prompt response to steroid treatment, was diagnosed. On the other hand, uveitis, high serum ACE, pathology of transbronchial and lymph node biopsy specimens were compatible with sarcoidosis.

Idiopathic CEP is a rare disease of unknown origin characterized by respiratory and systemic symptoms, alveolar or blood eosinophilia, peripheral infiltrates on chest imaging with prompt response to steroid treatment [1-6]. CEP may be associated with other diseases $[7,8]$. 
Two cases of sarcoidosis and CEP coexistence have been reported $[9,10]$.

BAL eosinophilia was $48 \%$ in our patient. This may be a feature of sarcoidosis but the increases are usually less than $8 \%$ and develop only in $5 \%$ of the patients $[11,12]$. In a review of 140 sarcoidosis patients, $14 \%$ had peripheral eosinophilia without any increase in lung eosinophils [13]. Diseases that may cause eosinophilic infiltration of the lung were excluded and there was no history of exposure to any kind of inorganic dusts or occupational agents. The patient did not have any infectious or parasitic diseases. Collagen vascular diseases and vasculitic syndromes were excluded because the rheumatologic markers were negative with no evidence of vasculitis in the biopsy specimens.

In this case, chronic eosinophilic pneumonia overlapped with sarcoidosis. The patient had symptoms of both diseases. The predominant nature of systemic symptoms with a high blood and BAL eosinophilia indicated CEP while presence of uveitis, high serum ACE, and non-caseating granulomas in TBLB pointed out to sarcoidosis. Consequently, the final diagnosis was sarcoidosis with coexistent chronic eosinophilic pneumonia. Systemic symptoms, blood eosinophilia, radiologic manifestations and BAL eosinophilia had prompt response to steroid treatment.

Eosinophilic lung diseases may occur due to a wide spectrum of pulmonary, or systemic etiologies [12,14]. Coexistence of sarcoidosis and CEP is a diagnostic challenge for the clinician because this occurence is extremely rare. Predominance of systemic symptoms with high peripheral eosinophil count are the most significant clues for the presence of chronic eosinophilic pneumonia coexisting with sarcoidosis.

\section{REFERENCES}

[1] Fox, B. and Seed, W. (1980) Chronic eosinophilic pneumonia. Thorax, 35, 570-580. http://dx.doi.org/10.1136/thx.35.8.570

[2] Wubbel, C., Fulmer, D. and Sherman, J. (2003) Chronic eosinophilic pneumonia: A case report and national survey. Chest, 123, 1763-1766. http://dx.doi.org/10.1378/chest.123.5.1763

[3] Naughton, M., Fahy, J. and Fitzgerald, M.X. (1993) Chronic eosinophilic pneumonia. A long term follow-up of 12 patients. Chest, 103, 162-165. http://dx.doi.org/10.1378/chest.103.1.162

[4] Hayakawa, H., Sato, A., Toyoshima, M., et al. (1994) A clinical study of idiopathic eosinophilic pneumonia. Chest, 105, 1462-1465. http://dx.doi.org/10.1378/chest.105.5.1462

[5] Carrington, C.B., Addington, W.W., Goff, A.M., et al. (1969) Chronic eosinophilic pneumonia. New England Journal of Medicine, 280, 787-798. http://dx.doi.org/10.1056/NEJM196904102801501

[6] Hayakawa, H., Sato, A., Toyoshima, M., Imokawa, S. and Taniguchi, M. (1994) A clinical study of idiopathic eosinophilic pneumonia. Chest, 105, 1462-1466. http://dx.doi.org/10.1378/chest.105.5.1462

[7] Grantham, J.G., Meadows III, J.A. and Gleich, G.J. (1986) Chronic eosinophilic penumonia: Evidence for eosinophilic degranulation and release of major basic protein. American Journal of Medicine, 80, 89-94. http://dx.doi.org/10.1016/0002-9343(86)90053-7

[8] Gaensler, E.A. and Carrington, C.B. (1977) Peripheral opacities in chronic eosinophilic pneumonia: The photographic negative of pulmonary edema. AJR, 128, 1-13. http://dx.doi.org/10.2214/ajr.128.1.1

[9] Tani, K., Kasho, M., Sano, N., Nalamura, Y., Ogushi, F. and Sone, S. (1998) A case of sarcoidosis associated with chronic eosinophilic pneumonia. Journal of Investigative Medicine, 45, 131-136.

[10] Shijubo, N., Fujishima, T., Morita, S., Nakata, H., Satoh, M., Uno, E., Morikawa, T. and Abe, S. (1995) Idiiopathic chronic eosinophilic pneumonia associated with non-caseating granulomas. European Respiratory Journal, 8, 327330. http://dx.doi.org/10.1183/09031936.95.08020327

[11] Allen, J.N., Davis, W.B. and Pacht, E.R. (1990) Diagnostic significance of increased bronchoalveolar lavage fluid eosinophils. American Review of Respiratory Disease, 142, 642-647. http://dx.doi.org/10.1164/ajrccm/142.3.642

[12] Allen, J.N. and Davis, W.B. (1994) Eosinophilic lung diseases. American Journal of Respiratory and Critical Care Medicine, 150, 1423-1438. http://dx.doi.org/10.1164/ajrccm.150.5.7952571

[13] Renston, J., Goldman, E., Hsu, R., et al. (2000) Peripheral blood eosinophilia in association with sarcoidosis. Mayo Clinic Proceedings, 75, 586-590. http://dx.doi.org/10.4065/75.6.586

[14] Jederlinic, P.J., Sicilian, L. and Gaensler, E.A. (1988) Chronic eosinophilic pneumonia. A report of 19 cases and a review of the literature. Medicine (Baltimore), 67, 154162.

http://dx.doi.org/10.1097/00005792-198805000-00002 